\title{
Representaciones sociales: marco para la interpretación comunicativa del conflicto y la paz
}

LisSetT M. EsPinel ToRres

E n este capítulo se tratará la categoría de representaciones sociales, como un criterio teórico para fundamentar la idea de que los medios agencian buena parte de las prácticas culturales en la comunidad en general, y que de alguna manera estos juegan un papel importante en la construcción de la representación social sobre los acontecimientos de la realidad social.

En primera instancia, se abordarán las definiciones que subyacen al concepto de representaciones sociales, pues se puede decir que dicha teoría aún sigue en un vasto desarrollo y en una constante discusión académica. En segunda instancia, se establecerán las diferentes discusiones, se ubicarán los elementos comunes y los contrastes en los significados otorgados desde las explicaciones elaboradas por distintos teóricos en la materia.

Los referentes del análisis son tomados de los documentos: Representaciones sociales. Teoría e investigación (2007) de Tania Rodríguez Salazar y María de Lourdes García Curiel de la Universidad de Guadalajara, quienes conceptualizan la representación social con relación a varios campos interdisciplinarios, cuyos contenidos colaboran, a manera de contexto histórico, en la definición de cómo y cuándo se desarrolla este concepto. Contribuye a lo expuesto, el texto de Prácticas Sociales y Representaciones (1994) de Jean Claude Abric, 
autor que se presenta como fuente principal del análisis. A su vez la obra Las representaciones sociales: Ejes teóricos para su discusión (2002), de Sandra Araya, que permite ahondar en la epistemología sobre representaciones sociales, dado que su mirada se basa tanto en las prácticas comunes como en los códigos que comparten las sociedades.

No obstante, este apartado se apoyará en la mirada reflexiva del texto de Rodríguez (2003): Las representaciones sociales: entretejidos de la razón y la cultura, donde se hace un análisis de las relaciones entre "comunicación, razón y cognición" (p.3). Así, para ahondar en este micro universo teórico conceptual sobre la discusión propuesta en torno a las representaciones sociales, Ruíz (2003) hace aportes desde el terreno de la historia cultural.

Finalmente, en este capítulo se propone establecer un diálogo entre las múltiples definiciones y conceptualizaciones de las representaciones sociales, buscando que ello permita ubicar las distintas conceptualizaciones sobre las mediaciones y su responsabilidad en la construcción de lo público en el contexto del conflicto y la paz.

\section{Abordaje conceptual de las representaciones sociales}

Para construir un marco conceptual sobre las representaciones sociales es preciso contextualizar sus origines en el campo de la teoría científica; y para ello se aborda parte del texto de Representaciones sociales. Teoría e investigación (2007) de Tania Rodríguez Salazar y María de Lourdes García Curiel, quienes hacen un recorrido histórico y evidencian cómo la teoría de las representaciones sociales hace su aparición en el campo de la psicología social en 1961, con los estudios realizados por Serge Moscovici de la escuela clásica, y cuya teoría ha servido como base para otras disciplinas y muy posiblemente se hizo con el fin de generar las relaciones establecidas entre los hechos, es decir, la realidad y los procesos cognitivos, las ideas.

Sin embargo, hay que reconocer que quien dio la primera puntada fue Émile Durkheim, cincuenta años antes que Moscovici, dando los 
primeros acercamientos y fundando todo un campo filosófico; por ello, para construir de manera rápida al recorrido histórico de cómo se inició la investigación en el campo del conocimiento social en la Modernidad, es importante revisar la voz de la doctora Denise Jodelet, profesora de la Universidad de París y reconocida científica, quien hace parte de la corriente histórica, como lo demuestra en su libro Pensamiento social e Historicidad (2003), donde manifiesta que el origen del concepto fue un tanto libertario, pero solo cuando se da el debate en el campo histórico y en la psicología, es cuando la academia piensa en un valor científico y le quita un poco la mirada empírica, otorgándole un valor significativo en el campo de los estudios sociales:

La función crítica nos recuerda la que revistieron en el campo histórico, la historia de las mentalidades y en el campo de la cognición social, el acercamiento en términos de representaciones sociales. Esta función, de algún modo prioritaria, da cuenta del carácter aproximativo de las perspectivas avanzadas en psicología social, como "lo borroso", lo más o menos conceptual, subrayadas a propósito de las nociones de mentalidad y representación social. Se trata aquí sin duda de una etapa transitoria y debemos de reconocer que este "más o menos" tuvo un carácter "liberatorio" y un valor heurístico, tanto en la historia como en la psicología. Ahora que nuevos territorios son balizados y desbrozados, se trata de encontrar el paso de la función crítica a la función constructiva. (Jodelet, 2003, p.100)

Con la propuesta de la profesora Jodelet (2003), también se puede descifrar que el carácter definitorio académico que obtuvo el concepto de la representación social como tal, se dio hasta la llegada de nuevos territorios epistémicos y que no se fundó solamente en el campo disciplinar de la psicología. Por su parte Jean Claude Abric plantea en su texto Prácticas sociales y representaciones (1994), que: "el campo de la psicología como la disciplina núcleo, es la que permite entender el estudio de las representaciones" (Rateau y Monaco, 2013, p.29): 
Para nosotros así como al parecer para Flament ( $c f$ cap. 2), la homogeneidad de una población no se define por consenso, pero sí por el hecho de que su representación se organiza alrededor del mismo núcleo central, y del principio generador, de la significación que otorgan a la situación o al objeto al que están confrontados. Es en este sentido que el estudio de las representaciones sociales nos parece esencial en psicología social, porque ofrece un marco de análisis y de interpretación que permite entender la interacción entre el funcionamiento individual y las condiciones sociales en que los actores sociales evolucionan. Permite entender los procesos que intervienen en la adaptación sociocognitiva de los individuos a las realidades cotidianas y a las características de su entorno social e ideológico. (Rodríguez y García, 2007, p.28)

Es Jean Claude Abric (1994) quien reflexiona sobre la tendencia que las relaciones entre prácticas y representaciones sociales se dan por un conjunto socio cognitivo, que se establece por un orden específico dado por la realidad social, es decir, lo determina como un doble enfoque muy desde la psicología, idea que se precede por su apoyo en el reconocido Moscovici:

El análisis y la comprensión de las representaciones sociales y de su funcionamiento supondrán así, siempre, un doble enfoque, un acercamiento que calificamos de sociocognitivo y que integra los dos componentes de la representación. Su componente cognitivo primeramente: la representación supone, lo hemos dicho, un sujeto activo, $y$ tiene desde ese punto de vista una "textura psicológica», sometida a las reglas que rigen los procesos cognitivos. Su componente social en seguida: la puesta en práctica de esos procesos cognitivos está determinada directamente por las condiciones sociales en que una representación se elabora o se transmite. Y esta dimensión social genera reglas que pueden ser muy distintas de la «lógica cognitiva». (Abric, 1994, pp.13-14)

Ambos componentes (cognitivo y social), como los denomina Abric (1994), son de cierta manera los conjuntos socio cognitivos integrados 
a las prácticas dadas por las condiciones sociales, y estas razones son parte fundamental de su aporte en el debate conceptual. Sandra Araya (2002), de la Facultad Latinoamericana de Ciencias Sociales (FLACSO), contribuye puntualizando en su texto Las representaciones sociales: ejes teóricos para su discusión, que los componentes de las representaciones sociales se pueden leer a partir de una lógica doble:

Se constituyen, a su vez, como sistemas de códigos, valores, lógicas clasificatorias, principios interpretativos y orientadores de las prácticas, que definen la llamada conciencia colectiva, la cual se rige con fuerza normativa en tanto instituye los límites y las posibilidades de la forma en que las mujeres y los hombres actúan en el mundo. (Araya, 2002, p.11)

Por su parte Óscar Rodríguez, de la Universidad Autónoma Metropolitana de Iztapalapa, en su texto Las representaciones sociales: entretejidos de la razón y la cultura (2003), aporta una definición con respecto a las relaciones entre los campos, expuestos anteriormente, que son nombrados como Razón y Cultura, elementos fundamentales para explicar o dar sentido al concepto de representación social; para tal fin el profesor Rodríguez señala que:

Las representaciones son necesariamente la expresión de cualquier grupo. Bajo esta condición son también la expresión de algún individuo. No al revés. Ya que el individuo, en cuanto tal, solo a condición de provenir de un grupo. En la medida que los individuos son comparados en función de las referencias de los grupos de donde provienen, es que surge la cuestión de las actitudes. (Rodríguez, 2003, p.5)

Las definiciones expuestas sobre lo que puede llegar a considerarse como representaciones sociales, se complementan con las reflexiones del profesor Juan Carlos Ruiz del Colegio de Michoacán, quien en su libro Representaciones colectivas, mentalidades e historia cultural: a propósito de Chartier y el mundo como representación (2003) argumenta que: 
La reflexión de corte historicista permitió mantener la atención sobre las peculiaridades de la dimensión temporal en el análisis histórico, prefigurando los nuevos puntos de discusión en cuanto a la variabilidad de las representaciones históricas, no solo las generadas por el discurso historiográfico, sino también las correspondientes a cada época. En este último terreno el historicismo también influyó en el interés por estudiar la historia de las ideas como la historia de las representaciones del mundo. Durante la primera mitad del siglo xx las tendencias estaban predominantemente acotadas en lo que a la representación en la historia se refiere: por un lado, el positivismo mantenía su postura por controlar las representaciones en el discurso histórico con miras a evitar la tan temida subjetividad (empresa fallida del todo); por el otro lado, el historicismo y sus diversas tendencias incrementaron el interés por hacer de las representaciones históricas y sus transformaciones el objeto de sus indagaciones, y no solo como una conciencia de que el discurso historiográfico se constituye a final de cuentas en una representación más. (Rodríguez, 2003, pp.23-24)

Para converger, es importante valorar cómo en el campo de la investigación se debate sobre el concepto de representaciones sociales, el cual se ha usado en el terreno de la práctica de las realidades sociales. Como práctica metodológica, a las representaciones sociales se las ha considerado como la estrategia para entender el pensamiento humano, de acuerdo a las necesidades teóricas que se le apliquen. No obstante, las diferentes disciplinas han manifestado que como objeto de estudio, las representaciones sociales son un referente para identificar, en doble vía, los procesos cognitivos fabricados por la sociedad, a medida de la evolución histórica del hombre. Lo anterior lo refuerza la corriente psicológica en la que se suscribe Agustín Moñivas, de la Universidad Complutense de Madrid, en su texto Epistemología y representaciones sociales: Conceptos y teorías (1994):

Si definimos la psicología, desde una perspectiva actual e integradora, como la ciencia de la actividad mental y conductual, las representaciones sociales tratan de dar cuenta de los aspectos sociales de 
esta actividad. De tal modo, que esta es probablemente la aportación más importante de la RS (Representaciones Sociales) no solo a la psicología social, como manifiestan McKinlay, et al. (1993), sino a toda psicología, habiéndose convertido en el objeto central de estudio de las ciencias sociales. Alrededor de las RS se ha construido un área de investigación dotada de instrumentos metodológicos y conceptuales propios. La noción de RS no pertenece a una disciplina determinada, de ahí la diversidad de definiciones en las distintas ciencias humanas, así como en las múltiples especialidades de aquellas en las que se aplica. (Moñivas, 1994, pp.409-419)

En el siguiente apartado se describen las potenciales discusiones que sobre las representaciones sociales se han dado a lo largo del campo académico, desde su aparición como método y desde los aportes epistémicos, para abordar la investigación en las disciplinas sociales.

\section{Discusiones epistémicas sobre representaciones sociales}

Dadas las definiciones sobre las representaciones sociales, se infiere que puede haber un marco general comparativo que ayude en el proceso de relacionar su significado en términos de similitudes y contrastes, frente a ello, la doctora Denise Jodelet (2003) señala que:

En razón de su nivel de acercamiento de los fenómenos, el estudio de las representaciones sociales puede ser considerado como un lugar privilegiado de convergencia y de apoyo mutuo entre historia y psicología. Esta reciprocidad de perspectivas se observa sobre todo en el caso de la historia de las mentalidades. En efecto, las nociones de mentalidades y de representaciones sociales se cubren si no corresponden stricto sensu. El examen de sus imbricaciones y de sus hiatos puede servir a establecer puentes entre las dos disciplinas. (Jodelet, 2003, p.105) 
Actualmente se está generando una discusión frente a los contrastes que hay entre el método de investigación y el objeto de estudio de las representaciones sociales; surgen así dos componentes (el cognitivo y el social) como elementos prácticos a la hora de clasificar por grupos a cada definición. Abric (1994) determina cada campo de la siguiente manera: componente cognitivo: proceso lógico del pensamiento en el que las ideas toman importancia, son valoradas por un grupo social, quién interpreta los componentes de acuerdo a los postulados epistémicos de la historiografía, cuyo fin fue el de incluirla como una categoría cognoscitiva y analítica en los estudios sociales; si bien todas las definiciones del concepto de representación apuntan a los mismos postulados, se verá cómo autores como Óscar Rodríguez (2003) generaron un cambio de rótulo frente a este componente, pero que no interfiere mucho con la conceptualización que hace el profesor Abric (1994) al nombrar al campo razón en lugar de campo cognitivo.

De todas maneras es imprescindible enfocarse en que semánticamente no hay contrastes de tipo categórico. Pero sí se tiene de relieve que ambas denominaciones son parte fundamental de la disciplina de la psicología. Nótese, entonces, cómo ambas posturas pueden contrastar aun cuando compartan casi la misma denominación lingüística y pertenezcan al mismo campo disciplinar de la psicología social; así pues, entre sí pueden existir dos variaciones o diferencias, que Abric (1994) destaca a partir de su hipótesis integradora de elementos organizados, que fuera de estar sistematizados, deben complementarse según su eje u objeto de estudio, y así lo específica en el siguiente fragmento:

Todos los autores después de Moscovici están de acuerdo con esta definición de la representación como conjunto organizado, pero nosotros hemos avanzado en una hipótesis respecto de esta organización interna: La hipótesis llamada del núcleo central que puede ser formulada en estos términos: la organización de una representación presenta una modalidad particular, específica: no únicamente los e1ementos de la representación son jerarquizados sino además toda representación está organizada alrededor de un 
núcleo central, constituido por uno o varios elementos que dan su significación a la representación. (Abric, 1994, p.18)

Para tal caso Rodríguez (2003) hace énfasis en cómo la Razón sirve para explicar que dicho componente hace parte de la metacognición; es decir, que eleva el concepto a ciencia de ciencia. Por otro lado, desarrolla la idea de que más allá de una mera relación con el pensamiento, también hay todo un proceso para volver esos códigos factores relevantes para un grupo social. La razón, entendida como el contenido colectivo para comprender los fenómenos suscitados por las dinámicas riesgosas que se crean entre los actores sociales por sus dogmas; dado que, en teoría estos grupos operan desde la concepción individual más que por la grupal.

Otro elemento clave para la comprensión del concepto de representación es al que alude Jean Claude Abric (1994) como componente social, siendo esta la segunda categoría que apunta más a una dimensión social, que puede distar de la simple lógica cognitiva:

En efecto: una segunda característica esencial de las representaciones sociales tal como las consideramos — que todavía aquí puede aparecer como contradictoria- es que esas representaciones sociales son alcanzadas por consenso y a la vez marcadas por fuertes diferencias interindividuales. Porque como lo señala «la identidad de los principios de regulación no impide en forma alguna la diversidad de las tomas de posición que se manifiestan por medio de actitudes y opiniones... Una multiplicidad aparente de tomas de posición producida [tal vez] a partir de principios organizadores comunes». El estudio de las representaciones sociales debe, por tanto tener en cuenta las diferencias interindividuales pero también permitir descubrir si esas diferencias son esenciales: es decir, si se sustentan sobre divergencias fundamentales relativas a su significación profunda y central o si manifiestan aprehensiones del mundo desde luego diferentes, pero que no se refieren a lo esencial. (Abric, 1994, p.27)

Mencionado ya, que como práctica metodológica en el campo de la investigación, el concepto se convierte en una causa para entender el 
pensamiento. Sin embargo, las disciplinas humanísticas han constituido como objeto de estudio el tema de las representaciones sociales, con el fin de observar las técnicas sociocognitivas.

Así que no hay diferencias tangenciales en ambos significados trabajos por Abric (1994) y por Rodríguez (2003), ya que se puede decir, que se utiliza dicho referente teórico como una plataforma para expresar que la cognición o la metacognición da como resultado la ciencia de la sociocognición, por cuanto una conduce a la otra. Al no existir punto divergente, la racionalidad se entiende como el cúmulo de creencias colectivas y, la cognición por sí sola son todos aquellas técnicas implementadas de manera individual, que le permiten al ser humano decodificar su propio entorno.

Sin embargo, la doctora Denise Jodelet señala que:

El llamado a la historia se hace de dos maneras. O sea por el estudio diacrónico de una representación, al comparar sus estados en dos épocas distintas, o sea reportándose a documentos históricos para seguir a largo plazo la evolución de una representación. (Jodelet, 2003, p.103)

Del mismo modo reafirma en su texto, que el método designado para el estudio de las representaciones para ambas disciplinas es el mismo:

En los dos casos se habla de actitudes, manera de pensar, marcos mentales, mecanismos intelectuales, representaciones, percepciones, imágenes, nociones, visiones, concepciones del mundo, modelos, valores etcétera. Común también, poner el centro sobre el aspecto colectivo, compartido por estos fenómenos y el medio enfocado. (Jodelet, 2003, p.105)

Ella ve seriamente que pueden haber distinciones entre los conceptos, tanto de la historicidad como del campo de la psicología social; en tal plano fundamenta su precepto en la concepción de que existe una preocupación común pero que hay también un tratamiento diferente en cuanto al aporte epistémico y sobre todo metodológico. 
En cambio Sandra Araya, trabajadora social de la Universidad de Costa Rica, se inclina por una mirada más hacia un enfoque cultural, y determina que:

El mundo de la vida cotidiana es aquel que se da por establecido como realidad. El sentido común que lo constituye se presenta como la "realidad por excelencia", logrando de esta manera imponerse sobre la conciencia de las personas, pues se les presenta como una realidad ordenada, objetivada y ontogenizada. (Araya, 2002, p.13)

Siendo la representación del mundo de la vida cotidiana, la visión con que se presupone la comunicación y la interacción. A lo anterior se añade lo que señala Araya (2002), quien cree que lo más importante está en la construcción de la lengua como punto neurálgico de la cultura popular, que permita crear una identidad social. En efecto y de manera concreta, la doctora Araya evidencia que coexiste entre los puntos de vista una posible divergencia:

Efectivamente, en este aspecto existen puntos de vista divergentes. Por un lado hay quienes señalan que las propiedades objetivas pueden ser descritas por observadores objetivos y observadoras objetivas. Agregan, además, que dichas propiedades pueden ser reconstruidas de forma incompleta y sesgada por los distintos protagonistas sociales en función de sus intereses particulares, de sus posiciones sociales, de sus experiencias culturales y de sus influencias culturales. De esta forma, la realidad objetiva se convierte en las realidades personales, siguiendo un proceso de distorsión que responde, él también, a determinaciones perfectamente objetivables. (Araya, 2002, p.14).

Puesto que es una franja muy delgada eso de los contrastes y similitudes, y si se llegan a dar, se puede decir que dichos conceptos son fabricados con cierta subjetividad, siendo tan relativo el tema, como lo es cada interpretación disciplinar. No se olvide que las fronteras del conocimiento son equivalentes a la estructura social, las condiciones 
sociocognitivas están dadas para que haya una diferencia desde lo étnico, desde cada grupo racial y su historia evolutiva. A esto, tal vez la historiografía podría llamarlo como la sincronía del desarrollo social o como elemento contrario, lo asincrónico; porque si bien las épocas, por distintas que sean, marcan una diferencia cognitiva en los grupos sociales, y además no existe una brecha cognitiva tan severa entre una u otra civilización. ¿Acaso las anteriores generaciones desconocieron más allá los acontecimientos de su propia realidad, cómo las futuras civilizaciones podrán desconocer la suya?

Otra posición, por el contrario, señala que la realidad presenta una serie de propiedades que, aun y siendo "realmente" constitutivas de la misma, no dejan de ser absolutamente subjetivas. o sea, son propiedades que conforman la realidad objetiva, pero que resultan de las actividades cognitivas y, en términos más generales, de las actividades simbólicas desarrolladas por las personas, esto implica que la realidad tal y como es, está parcialmente determinada por la realidad tal y como es para las personas. Significa ello que, en cierta medida, la realidad pasa a ser el resultado -o el producto- de la construcción subjetiva que de la misma realizan las personas. Según está posición, no es que existan diferentes realidades porque existan diferentes maneras de tratar la misma realidad objetiva, sino que existen diferentes realidades porque la propia realidad incorpora en sí misma, y como parte constitutiva de sí misma, una serie de características que provienen de la actividad desarrollada por las personas en el proceso que les lleva a formar su propia visión de la realidad. El punto álgido de la discusión es entonces la existencia de diversas realidades subjetivas y en particular lo que respecta a la descripción de sus características o la lógica de su elaboración. Y son estos aspectos, precisamente, los que quieren resolver las investigaciones sobre las RS. (Araya, 2002, p.15).

La cuestión pone de relieve la algidez que conlleva tratar de objetivizar una definición teórica, sobre todo en el campo de las ciencias sociales; siendo este último aspecto un terreno variante por su base 
epistémica compartida en el silogismo de las disciplinas humanas. El tratar de comprender los aspectos sociales, desde sus variantes del pensamiento como de los comportamientos colectivos. Es como tratar de sistematizar percepciones individuales que son tan fluctuantes como el mismo ser humano lo ha demostrado a través del avance cultural. Que en palabras de Araya:

Una condición inherente en los estudios de representación social es la identificación del contexto social en el cual se insertan las personas que elaboran las R S, pues se busca detectar la ideología, las normas y los valores de personas e instituciones y los grupos de pertenencia y referencia. En los estudios de cognición se manipulan variables independientes a fin de observar sus efectos sobre los mecanismos mentales individuales independiente de los contextos sociales. (Araya, 2002, p.16)

Nótese cómo ya hay una diferencia marcada entre ambos campos: primero los estudios de cognición, se inclinan a los estudios mentales individuales y el segundo, basa su condición en el esbozo de la teoría socio histórica, cuyo objeto siempre tiene en cuenta los contextos; con el fin de identificar lo más importante, la ideología de los grupos sociales.

Avanzando en la conclusión de la tercera parte de este capítulo, se subraya cómo se va acercando a la postura de lo que se comparte como significado en este estudio, específicamente, sobre la representación de la guerra y de la paz, tema presente en el capítulo dos de este documento.

Por cuanto hay dos criterios fundamentales para pensar los procesos comunicativos, que por ende son de corte comunitario, que las poblaciones los desarrollan en torno a una realidad mediada por una condición dada por su territorio, que de por sí ya es hostil y condicionado a la pobreza por una tradición azotada por la violencia; sin embargo la comunidad valiente hace una propia lectura de su cotidianidad de cara a un posible proceso de paz, que se puede dar o no en la actualidad en La Habana Cuba. Dejando la práctica de un lado, Araya es explicita cuando demuestra en su texto cómo se ve el fenómeno de 
las interpretaciones en cualquier campo a diagnosticar, desde lo concerniente a la teoría:

\begin{abstract}
Por su parte, las personas son concebidas como seres que piensan autónomamente y que producen y comunican constantemente representaciones y no como meras receptoras pasivas, por lo que cualquier determinismo social es rechazado. En la construcción de la realidad social el papel del Alter es significativo. Las personas se relacionan entre sí y en esta relación con los otros y las otras, elaboran observaciones, críticas, comentarios y "filosofías" no oficiales que tienen una influencia decisiva sobre sus escogencias, formas de educar a sus hijos e hijas, en la elaboración de sus planes, etcétera. (Araya, 2002, p.8)
\end{abstract}

Se ha decidido finalmente entrar en materia con la definición del objeto de estudio de las representaciones sociales para contextualizar los capítulos que siguen acerca de la forma en que la alter comunicación se desarrolla en zonas de conflicto armado. En la interpretación del conflicto social y armado de Colombia, las tres experiencias comunicativas: Ocaina estéreo, Ingakuna estéreo, Piamonte estéreo, que se describen en el capítulo tres, permiten inscribirnos en una corriente teórica cognitiva sobre la doble vía conceptual de las representaciones, pues estas nos suscriben en una práctica de las representaciones de la alter-comunicación.

\title{
Representaciones para interpretar las dinámicas del conflicto y la paz
}

Antes de avanzar en este punto es importante insistir en la necesidad de esquematizar la condición que imponen los medios masivos de información en Colombia cuando se trata de fabricar imaginarios colectivos sobre la violencia o la paz en Colombia: 
Los medios, además del lugar institucional que ocupan, construyen permanentemente una imagen de omnipresencia que les permite establecer la agenda. Al mismo tiempo construyen una imagen del receptor; en definitiva construyen una imagen de la relación entre los medios y los receptores o consumidores de los productos de los medios. (Raiter, 2001, p.9)

Ahora bien, como no es un pretensión elaborar aquí un concepto teórico, sino desarrollar algunas nociones para lograr entablar más que una discusión un diálogo que provea de elementos identificadores: pueden existir muchas coincidencias teóricas, muchas intencionalidades afines al espacio que se pretende reconstruir, sin embargo, la teoría de las representaciones sociales aspira a la prueba, mientras que la historia cultural aspira a una correcta lectura del indicio. Ni siquiera la historia cultural escapa a los viejos debates sobre las posibilidades frente al pasado (Rodríguez, 2003, p.49).

El problema para entrar en este campo epistémico, es que hay que reconocer el contexto que se abrevió anteriormente, puesto no hay manera de no involucrar dentro de un estudio del pensamiento moderno social, la teoría científica de la representación, Pues esta da muestra de un compendio metodológico que extrapola los posturas ideológicas de los grupos poblacionales. Por ende no se puede homogeneizar el pensamiento colectivo, por lo menos en esa parte se está de acuerdo con Rodríguez (2003).

El concepto de representación tiene su lado sugestivo. Atrae la atención del observador y del investigador de los núcleos humanos. Tal vez esto se explica porque ellas se alejan del discurso ideológico. Las formas del entendimiento común son diversas, plurales, múltiples. No pretenden decir cómo es el mundo sino aproximársele, aquí radica la variedad. En la diversidad la gente sabe, acumula experiencias y aprende a discurrir. La ideología es cerrada, produce un discurso dogmático con alma de hegemonía. (Rodríguez, 2003, p.93) 
El concepto que se alude acá, es el mediado por la cultura, la razón, y los estudios del lenguaje como elaboración cognitiva de las representaciones sociales; estas relaciones halladas en los autores referenciados en este análisis, permiten una mirada hibrida, por cuanto los estudios de representación no tienen hasta ahora un modelo estándar, que no estimule la libertad epistemológica como la metodológica, cuyo mayor aporte es el de reconocer, primero, la participación activa de la comunidad, en donde la labor etnográfica, de trabajo de campo hace su aparición.

Además, el método más apropiado para llegar a los grupos poblacionales es el sistema de las entrevistas y sobre todo la fidelización de las voces en sus testimonios, con el fin de extraer las posturas ideológicas, para procesar los cambios y las maneras de ver y entender su mundo. Cabe señalar, en esta parte, que los medios han jugado un papel decisivo en el pensamiento colectivo moderno, ya que no se concibe el mundo sin esa mirada o perspectiva. Se asiste a un mundo en incertidumbre, que todo y nada es posible, se aprende a ser sujetos insensibles frente a un escenario que no es real del todo. Los matices y las interpretaciones mediáticas, producen contenidos en los imaginarios colectivos; no obstante, para profundizar más la opinión es necesario ampararse en la acertada pero discrecional posición de Rincón, García, y Zuluaga, en su texto La Nación de los medios (2008), quienes señalan que:

Los medios de comunicación masiva se han convertido en las fuentes desde las cuales se determina la conciencia, la conducta, los sueños, los miedos y las esperanzas de los sujetos y colectivos sociales. Los medios masivos han dejado de registrar la realidad para pasar a producirla. Y al mirarnos en esos espejos masivos, las imágenes que vemos nos muestran que no estamos satisfechos con el cómo venimos siendo, nos sentimos precarios frente a los ideales mediáticos de lo que debemos ser. En estos tiempos mediáticos, asistimos a una crisis de referencia, hemos perdido el control sobre las imágenes de quiénes somos o queremos ser porque los medios masivos se han convertido en una fuente importante para evaluar y comprender nuestras experiencias. (Rincón, García y Zuluaga, 2008, p.7). 
Entonces, la pregunta a contemplar en este estudio sería: ¿cómo los medios representan la violencia en Colombia? La representan con un solo interés, el de estabilizar por medio de los relatos un posible control social, que está determinado por una gran dosis de morfina en sus contenidos. Para lo cual Omar Rincón en su capítulo La Nación como un happening mediático (2008) publicado en el texto La Nación de los medios tiene a bien en suscribir a los medios como el sitio de encuentro entre poderes:

Los medios de comunicación han determinado las formas de hacer la política en la sociedad contemporánea, ya que se han establecido como el escenario prioritario para el debate de las ideas; el dispositivo preferido y más efectivo para comunicarse entre gobiernos y ciudadanos, políticos y candidatos; el mecanismo preferido para consultar las opiniones de la sociedad; el lenguaje más atractivo para construir consensos y disensos. En este sentido, todos los elementos de la política han sido transformados y extendidos por los medios de comunicación. Mientras antes se actuaba guiados por ideologías e ideas de gran aliento, con los medios de comunicación la política busca estilos contundentes desde la imagología e ideas instantáneas y efímeras para convocar más al individuo que a la sociedad como colectivo. (Rincón, García y Zuluaga, 2008, p.13)

Así que se asiste a la controversial, pero muy marcada representación discursiva que mantienen los medios masivos de la información, pues como lo señala Rincón (2008), el medio es un escenario que se mimetiza para cada función especial que se quiera recrear, y en esa parte estamos totalmente de acuerdo; por cuanto son los medios quienes dan lugar a lo representado, que en el caso del tema de la violencia en Colombia, son los que han insensibilizado a la mayoría de la población. En tal sentido, se puede prever que en el campo colombiano no se da dicha influencia mediática, es decir, sucede lo contrario porque muchas veces no llegan las señales de televisión nacional, y menos la señal por cable; para comenzar no hay luz eléctrica, no hay agua potable, no hay vías de acceso, lo que sobra es pobreza; pero lo que sí se puede establecer es que hay colombianos menos engañados por estas 
subrealidades contadas por los medios masivos de información; así que lo apremiante son las experiencias mismas, constituyendo los referentes para las poblaciones campesinas.

Aquí es donde juega un papel importante la definición del tema de las representaciones sociales, porque al plantearse el interrogante de ¿cómo diferenciar la representación que han asumido el mayor común denominador de los colombianos respecto al resto de pobladores que se encuentran distanciados del dominio mediático? se hallan conexiones dialógicas, entre muchos conceptos tratados atrás sobre las representaciones, para así lograr acogerse a la que identifique un canal metodológico de investigación que posibilite un proceso sistematizado, para descubrir el pensamiento social-colectivo de las tres experiencias de alter medios 1. Ocaina estéreo, 2. Ingakuna estéreo, 3. Piamonte estéreo.

Para tal fin, los referentes comunes, en este caso la violencia, no cambia, y lo que se transforma es el contexto local, una cosa es conocer la realidad de los territorios en zonas de conflicto tras una pantalla chica, y otra es vivirla y contarla en medio de la debacle. Eso fue lo relatado por las tres experiencias comunicativas, anteriormente descritas. Lo que permitió una reflexión de los imaginarios y cómo estaban contemplados por su propia cotidianidad y no por la que cuentan los medios nacionales.

Lo que incumbe es cómo hallar las representaciones del conflicto armado y la paz en procesos alter comunicativos. Pues, la producción de contenidos de los alter-medios y sobre todo en zonas de conflicto, son dadas desde los contextos de su propia cotidianidad, cuyas representaciones son interpretaciones elaboradas desde lo local. Dichas representaciones, entonces, están intervenidas por los actores de la guerra y los que conviven con ella por simple obligación; porque de alguna manera se niegan a dejar su territorio que por herencia ancestral y tradición tienen por derecho para vivir allí.

No obstante, el miedo y el abandono estatal hacen que los habitantes procuren recurrir a sus propios relatos como forma de plasmar la memoria en su territorio. El aprender a convivir con la violencia, es su mayor argumento. Aquí el discurso mediático, no interesa o no representa o no marca una ruta, una agenda en la comunidad. Los pobladores atañen a que dentro del discurso mediático ellos no aparecen, 
no son tomados en cuenta como un testimonio principal, son relegados del escenario tanto político como social.

Así, es preciso connotar que la mejor forma de acercarse a la representación de las experiencias ya nombradas, fue usando como estrategia teórica de las representaciones sociales, las que integran elementos estructurales como la actitud, la opinión, los estereotipos, la percepción social, las imágenes. Aspectos ya considerados y trabajados por el ilustre Serge Moscovici. Además, se quisieron aplicar estos elementos para poder identificar que hay todo un conocimiento socialmente elaborado por estas comunidades fustigadas por la violencia, y que lo más relevante fue encontrar la manera cómo se representa la disputa por el territorio y desde dónde se abarca dicho análisis, tema tratado a profundidad en los capítulos siguientes. 
